\title{
PENGEMBANGAN SISTEM INFORMASI JASA PENUKARAN VALAS
}

\author{
Anzaludin Samsinga Perbangsa ${ }^{1}$, Aloysius Reyner ${ }^{2}$, Joshua Christian Nugroho $^{3}$, Junne ${ }^{4}$ \\ Sistem Informasi, Universitas Bina Nusantara, Jakarta Indonesia \\ 1aperbangsa@binus.edu
}

Submission date: $2020-02-25$

Accepted date: 2020-03-25

\begin{abstract}
The role of money changers is very important in meeting the needs of foreign exchange for the community. This role can also be fulfilled by banks and other financial institutions. People who want to order foreign currencies at this time still have to go through traditional procedures, where the buyer is required to come directly to the place of foreign exchange. This study intends to build a system design that can make currency orders and provide information on foreign exchange rates contained in each money changer through a web-based application. This research uses the Object Oriented Analysis and Design (OOAD) method, literature study, and data collection methods using a questionnaire. Based on the problems outlined and the results of the study, this system can be a source of information on foreign exchange rates and also an alternative order for foreign exchange. Foreign exchange orders can be made online through this information system. This system will continue to be developed with various features such as payment methods using biometric security methods with the support of Artificial Intelligence (AI) technology. So users can search for foreign currency values and order them easily through online media.
\end{abstract}

Keywords: System Development, Information System, Valas OOAD,

\begin{abstract}
ABSTRAK
Peran money changer sangat penting dalam memenuhi kebutuhan valas untuk masyarakat. Peran tersebut juga dapat dipenuhi oleh bank dan institusi keuangan lainnya. Masyarakat yang hendak memesan mata uang asing saat ini masih harus melalui prosedur tradisional, dimana pemesan diharuskan untuk datang secara langsung ke tempat penukaran valuta asing. Penelitian ini bermaksud untuk membangun rancangan sistem yang dapat melakukan pemesanan mata uang dan memberikan informasi kurs mata uang asing yang terdapat pada setiap money changer melalui aplikasi berbasis web. Penelitian ini menggunakan metode Object Oriented Analysis and Design (OOAD), studi pustaka, dan metode pengumpulan data menggunakan kuesioner. Berdasarkan masalah yang dijabarkan dan hasil penelitian, maka sistem ini dapat menjadi sumber informasi pertukaran kurs valuta asing dan juga menjadi alternatif pemesanan valuta asing. Pemesanan valuta asing dapat dilakukan secara online melalui sistem informasi ini. Sistem ini akan terus di kembangkan dengan berbagai fitur seperti metode pembayaran menggunakan metode keamanan biometrik dengan dukungan teknologi Artificial Intelligence (AI). Sehingga pengguna dapat mencari nilai valas dan memesannya secara mudah melalui media online.
\end{abstract}

Kata Kunci: Pengembangan sistem, Sistem Informasi, Valas, OOAD

\section{PENDAHULUAN}

Ketersediaan teknologi internet semakin merata di masyarakat. Hasil survey pengguna internet di Indonesia APJII tahun 2017 menyatakan bahwa jumlah pengguna internet Indonesia pada tahun sudah mencapai 143 juta orang atau sekitar 55\% penduduk. Hal ini akan sangat menunjang peralihan bisnis proses dari cara konvensional menjadi melalui media online, termasuk dalam bisnis valas (APJII, 2017; B. APJII, 2018).

Pertukaran valuta asing (valas) menjadi sebuah kebutuhan penting yang hanya dilakukan jika ada kebutuhan tertentu, seperti berpergian ke luar negeri, transaksi jual beli internasional, atau saat kondisi politik ekonomi internasional yang tidak menentu. Valas dapat didefinisikan sebagai alat pembayaran dalam transaksi antar negara dimana Bank Indonesia sebagai bank sentral menetapkan kurs resmi (Wiguna, 2014). Valas tidak dapat ditetapkan secara permanen, faktor-faktor pendukung perekonomian suatu negara dapat mempengaruhi kekuatan mata uang. Fluktuasi naik turunnya nilai tukar valas mempengaruhi perilaku masyarakat dalam mengelola valas, disamping tingkat suku bunga, inflasi, dan faktor-faktor lainnya (Triyono, 2008). Masyarakat yang ingin bertransaksi diharuskan untuk hadir secara fisik di tempat pertukaran uang. 
Saat ini hampir semua orang mencari informasi pertukaran mata uang asing secara digital, selain kemudahan akses yang ditawarkan, informasi secara digital menghemat waktu dan tenaga. Bank sentral umumnya menjadi acuan utama dalam memperkirakan nilai tukar mata uang asing yang beredar, tetapi tidak semua menukarkan uangnya ke Bank sentral, berbagai alasan membuat penukaran mata uang asing dilaksanakan di money changer, sedangkan informasi nilai tukar mata asing pada sebuah money changer tidak selalu sama dengan apa yang ditampilkan pada Bank sentral (Amanda, Yasin, \& Prahutama, 2014; Kurniawan, 2013). Masyarakat membutuhkan informasi yang akurat untuk mengetahui nilai mata tukar uang asing yang diterapkan oleh money changer. Sistem ini dikembangkan untuk berjalan di atas platform berbasis web untuk memudahkan masyarakat melakukan penukaran uang melalui sistem ini. Sistem ini mempunyai batasan-batasan:

1. Hanya menggunakan data nilai jual beli mata uang yang berasal dari money changer yang terdaftar

2. Dibuat dalam platform web.

3. Sistem pembayaran yang digunakan adalah melalui transfer antar rekening bank.

Penelitian ini bertujuan sebagai berikut:

1. Mengidentifikasi masalah yang berhubungan dengan transaksi valuta asing yang ada di masyarakat Jakarta.

2. Mencari solusi untuk memecahkan masalah yang sudah diidentifikasi tersebut.

3. Merancang usulan sistem informasi yang mampu memecahkan masalah yang telah diidentifikasi.

\section{METODE PENELITIAN}

Adapun metodologi yang digunakan dalam penelitian ini terdiri dari:

1. Metode Studi Pustaka

Mengumpulkan data referensi yang berasal dari buku-buku yang berkaitan dalam penulisan landasan teori penelitian ini (Sugiyono, 2017).

2. Metode Pengumpulan Data

Membuat kuesioner online yang ditujukan kepada responden, dalam kuesioner ini berguna untuk mengambil data yang dapat berfungsi sebagai penyesuaian dalam mengembangkan sistem berbasis web agar dapat mendekati harapan responden (Creswell, 2013; Creswell \& Clark, 2017).

3. Metode Analisis
Business Canvas Model, dimana dalam model bisnis kanvas tersebut dapat melihat mana yang menjadi keunggulan dan apa saja yang berpengaruh terhadap bisnis, siapa yang menjadi pesaing, bagaimana mengelola sumber daya yang ada, dan bagaimana alur bisnis berjalan.

4. Metode Perancangan

Dalam merancang sistem, digunakan diagram dengan notasi UML. Unified Modeling Language (UML) adalah Bahasa yang telah telah menjadi standard untuk visualisasi, menetapkan, membangun dan mendokumentasikan artifak suatu sistem perangkat lunak (France, 2004). Unified Modeling Language (UML) adalah alat bantu analis serta pengembangan perangkat lunak berbasis objek (Nugroho, 2009). Diagram-diagram UML yang dibangun adalah Activity Diagram, Use Case Diagram, Domain Model Class Diagram, dan User Interface Design.

\section{HASIL DAN PEMBAHASAN}

Terdapat 10 pertanyaan dalam kuisoner ini. Hasil kuisoner yang telah disebarkan mendapatkan 53 responden. Dari jawaban responden yang di dapat, frekuensi responden yang pergi ke money changer sebanyak $70.1 \%$ dari jumlah responden meskipun frekuensi dalam satu bulan berbeda-beda. Responden juga sudah terbiasa dengan transaksi online, yaitu sebanyak $81.1 \%$ dari jumlah responden. Sebanyak $52.8 \%$ responden juga menganggap web yang menawarkan transaksi online lebih menarik (Sani, Rahman, Subiyakto, \& Wiliani, 2019). Dalam mencari referensi nilai mata uang asing, website bank menjadi pilihan utama setelah itu disusul oleh website money changer dan di urutan ketiga pergi langsung ke money changer. Untuk mengetahui alasan mengapa orang tidak sering pergi ke money changer, hasil responden menyatakan bahwa kebanyakan orang tidak memiliki waktu dan keinginan untuk pergi ke money changer, mereka beranggapan money changer perlu mengantri dan membutuhkan waktu lebih untuk menukarkan uang. Sebanyak $86.9 \%$ responden tertarik dengan adanya portal money changer yang nantinya memudahkan responden untuk melihat mata uang di setiap money changer tanpa harus datang ke setiap money changernya. Sebanyak $62.3 \%$ responden juga tertarik untuk mengharapkan adanya transaksi online di portal money changer tersebut. Dari hal tersebut responden mengharapkan fitur pemesanan online sebanyak $83 \%$,yang kemudian notifikasi dan grafik trend menempati urutan kedua dalam harapan responden sebanyak 66\%, dan yang berada di urutan ketiga yaitu fitur auto order ketika harga sudah sesuai dengan 
keinginan responden. Proses pengembangan OOAD terdiri dari tahapan menggali kebutuhan pengguna, analisa dan perancangan sistem, pemrograman,

Tabel 1. Business Model Canvas Jasa Penukaran Valas

\begin{tabular}{|c|c|c|c|c|}
\hline $\begin{array}{c}\text { Key } \\
\text { partner }\end{array}$ & Key Activities & Value Proposition & $\begin{array}{c}\text { Customer } \\
\text { Relationship }\end{array}$ & Customer Segment \\
\hline \multirow[t]{4}{*}{$\begin{array}{l}\text { - Money } \\
\text { changer }\end{array}$} & $\begin{array}{l}\text { - Menerima Pesanan } \\
\text { - Memesankan mata uang } \\
\text { asing } \\
\text { - Update status pesanan } \\
\text { - Promosi }\end{array}$ & \multirow[t]{5}{*}{$\begin{array}{l}\text { - Fitur Pengingat } \\
\text { - Pemantauan mata uang } \\
\text { asing } \\
\text { - Relasi money changer } \\
\text { - Pemesanan langsung secara } \\
\text { online }\end{array}$} & - Customer service & \multirow[t]{3}{*}{$\begin{array}{l}\text { - Orang yang hendak } \\
\text { menukarkan uang }\end{array}$} \\
\hline & Key Resource & & Channel & \\
\hline & $\begin{array}{l}\text { - Programer } \\
\text { - Customer Services } \\
\text { - Marketing } \\
\text { - Komputer } \\
\text { - Server }\end{array}$ & & $\begin{array}{l}\text { - Web } \\
\text { - Media Social }\end{array}$ & \\
\hline & Cost Structure & & \multicolumn{2}{|c|}{ Revenue Stream } \\
\hline \multicolumn{2}{|c|}{$\begin{array}{l}\text { Biaya hardware system } \\
\text { Gaji karyawan } \\
\text { Biaya pengembangan system }\end{array}$} & & \multicolumn{2}{|l|}{$\begin{array}{l}\text { Fee pemesanan pen } \\
\text { Iklan }\end{array}$} \\
\hline
\end{tabular}

Sumber : (anzaludin, 2019)
Bisnis model kanvas di buat agar bisnis dapat berjalan sesuai dengan yang harapkan. Bisnis model kanvas terdiri dari:

\section{Key partners}

Key partners merupakan koneksi antar perusahaan yang saling membantu dan mendukung proses bisnis. Sistem ini berhubungan dengan money changer sebagai mitra bisnis. Perusahaan yang masuk kedalam key partner adalah hal yang sangat vital karena dengan key partner tersebut bisnis dapat berjalan dengan baik. Hal yang mendukung key partner yaitu dapat mempromosikan money changer secara online melalui system ini.

\section{Key Activities}

Key activities adalah aktifitas-aktifitas utama sistem untuk menjalankan proses bisnisnya. Aktivitasaktivitas tersebut meliputi menerima pesanan, memesankan mata uang, update status pesanan, promosi. Dalam melakukan promosi online-offline dan direct marketing. Pemasaran online meliputi iklan di media sosial, dan iklan di internet, sedangkan pemasaran offline meliputi penyebaran flyer, dan pendirian kios di event-event yang berhubungan begitu pula dengan direct marketing di tempat-tempat ramai untuk mempromosikan ke masyarakat termasuk money changer.

3. Value Propositions

Value proposition merupakan nilai-nilai yang diberikan sistem kepada mitra dan juga kepada pelanggan agar sistem dapat tetap dipercaya oleh mitra dan pelanggan. Sistem ini memiliki fitur pengujian, implementasi dan integrasi, serta pembuatan bisnis model canvas (Satzinger, Jackson, \& Burd, 2011) notifikasi, pemantauan mata uang asing, relasi dengan money changer, dan pemesanan langsung menggunakan sistem. Dengan nilai-nilai tersebut, sistem dapat mempermudah pelanggan mencari mata uang di money changer dan juga money changer mencari pelanggan.

4. Customer Relationship

Customer relationships merupakan relasi yang di bangun kepada mitra yaitu money changer maupun kepada pelanggan. Usaha untuk membuat customer relationship yang baik yaitu memberikan pelayanan customer service sehingga mitra maupun pelanggan dapat mencari solusi ketika menghadapi suatu masalah pada sistem.

5. Customer Segments

Customer segments adalah segmentasi pelanggan yang menjadi target sistem ini, dalam hal ini masyarakat yang hendak menukarkan ke mata uang asing, sedangkan untuk mitra memiliki target money changer yang hendak memasarkan produk mereka kedalam bentuk online untuk mencari market yang lebih luas lagi.

6. Key Resources

Key resources merupakan sumber utama yang akan membantu menjadi berkembang dan untuk menjalankan bisnisnya. Dalam hal ini diantaranya adalah programmer untuk mengembangkan web, customer service menjadi pengendali di sistem backend, marketing, dan hardware.

7. Channels

Channels merupakan jaringan yang dapat membuat sistem menjadi tersebar luas dan dapat dinikmati oleh pelanggan maupun mitra. Dalam hal ini sistem 
menggunakan internet dan media sosial sebagai channels yang membantu sistem memperkenalkan ke masyarakat luas.

8. Cost Structure

Cost Structure merupakan rincian yang dikeluarkan sistem untuk membangun sistem dan biaya yang dikeluarkan untuk menjalankan proses bisnis yang ada. Cost structure sistem ini diantaranya pembelian sistem hardware, gaji karyawan, dan biaya pengembangan sistem.

9. Revenue Streams

Revenue stream merupakan suatu aliran dana yang didapatkan sistem dari proses bisnis menjadi keuntungan. Revenue stream sistem yaitu dari fee yang di dapatkan setiap pelanggan melakukan transaksi.

Platform sistem ini berbasis web, sehingga dibangun dengan bahasa pemrograman Hyper Text Markup Language (HTML) dan Hypertext Preprocessor (PHP). HTML telah menjadi standar pembuatan struktur komponen halaman web seperti teks, gambar, audio, dan video (Yudiastra \& Darma, 2015). PHP adalah bahasa interpreter di server yang memungkinkan terjadinya interaksi antara client dengan web server (Sibero, 2011). Sedangkan Web Server merupakan perangkat lunak di server yang berfungsi mengatur interaksi antara client dengan server (Supardi, 2010).

Activity diagram pada gambar 2 menjelaskan alur sistem yang di rancang. Customer dapat membuat harga yang diharapkan, yang nantinya ketika sudah mencapai harga yang sesuai maka sistem akan memberikan notifikasi kepada customer.

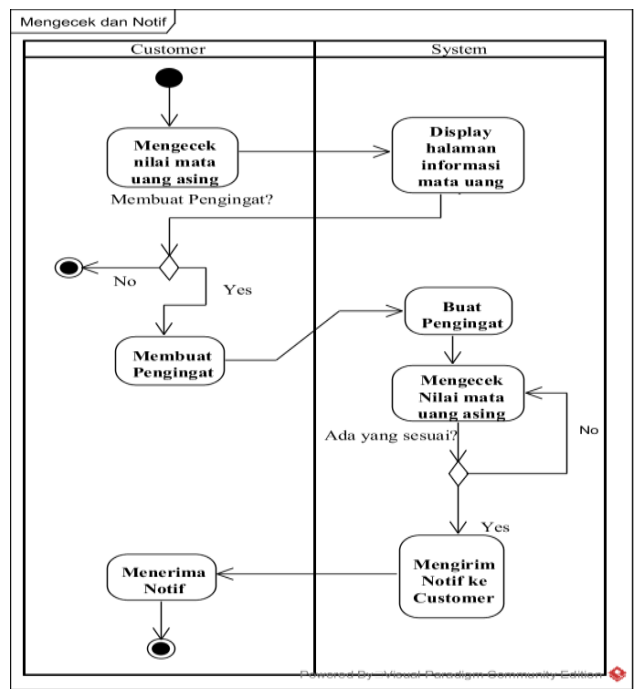

Sumber: (anzaludin, 2019)

Gambar 1. Activity Diagram Mengecek dan Membuat Notifikasi
Use case diagram pada gambar 3 di dalam sistem ini ini dibagi bedasarkan aktor yang melakukan kegiatan, yaitu customer, money changer, dan customer service.

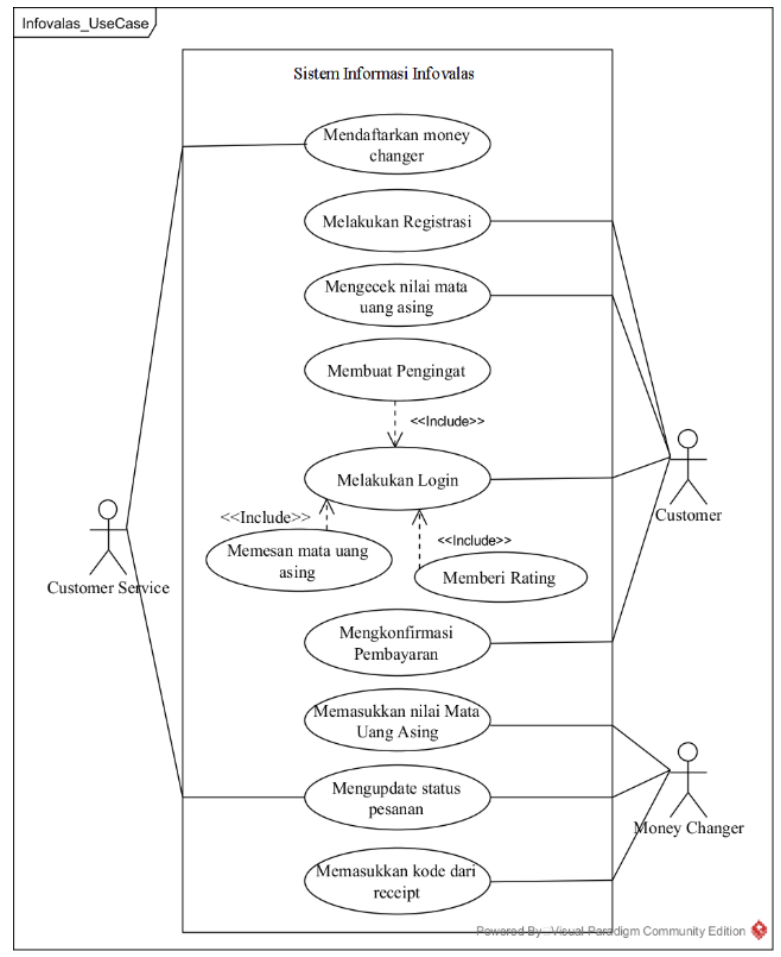

Sumber : (anzaludin, 2019)

Gambar 2. Use Case Diagram Sistem Infovalas

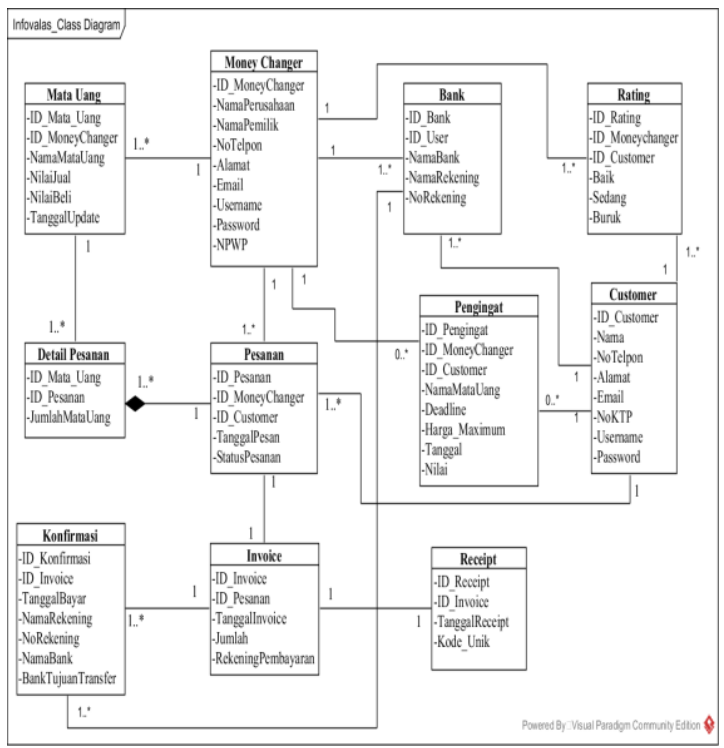

Sumber: (anzaludin, 2019)

Gambar 3. Logical Record Structur (LRS) Sistem Informasi Valas 
Domain Model Class Diagram pada gambar 4 merupakan gambaran hubungan setiap entity yang akan di kembangkan didalam sistem berbasis web ini. Diagram ini akan menjadi dasar struktur database. Database adalah suatu dataset yang saling terhubung secara logis dan ditujukan agar sesuai kebutuhan organisasi (Connolly \& Begg, 2005). Database juga didefinisikan sebagai himpunan data terintegrasi yang dapat digunakan oleh beberapa aplikasi.

Gambar 4 menunjukkan halaman tampilan menu Informasi mata uang, memuat informasi mengenaiharga jual dan beli mata uang yang terdapat pada sistem dan juga data kurs yang diberikan setiap money changer yang tercatat, informasi tersebut didukung oleh informasi mengenai kapan data kurs tersebut diupdate. Pada page ini pengunjung memiliki keleluasaan untuk melihat informasi mata uang berdasarkan nilai jual terendah ataupun nilai beli tertinggi terupdate. Fitur yang tersedia diantaranya adalah:

1. Baru Update

Menampilkan harga-harga yang baru saja money changer update atau tambahkan.
2. Pilih Mata Uang

Memilih mata uang yang ingin di tampilkan.

3. Nilai Jual Terendah

Menampilkan urutan money changer yang memberikan harga jual terendah sesuai dengan mata uang yang di inginkan.

4. Nilai Beli Tertinggi

Menampilkan urutan money changer yang memberikan harga beli tertinggi sesuai dengan mata uang yang di inginkan.

5. Reputasi Terbaik

Melihat reputasi terbaik dari semua money changer yang terdaftar.

6. Lihat Mata Uang di Money changer Untuk mengarahkan pada daftar mata uang yang tersedia di money changer terpilih.

7. Iklan

Menampilkan iklan informatif kepada pengunjung

8. Melihat Semua Daftar Terpilih

Melihat semua daftar sesuai dengan tab yang di pilihnya.

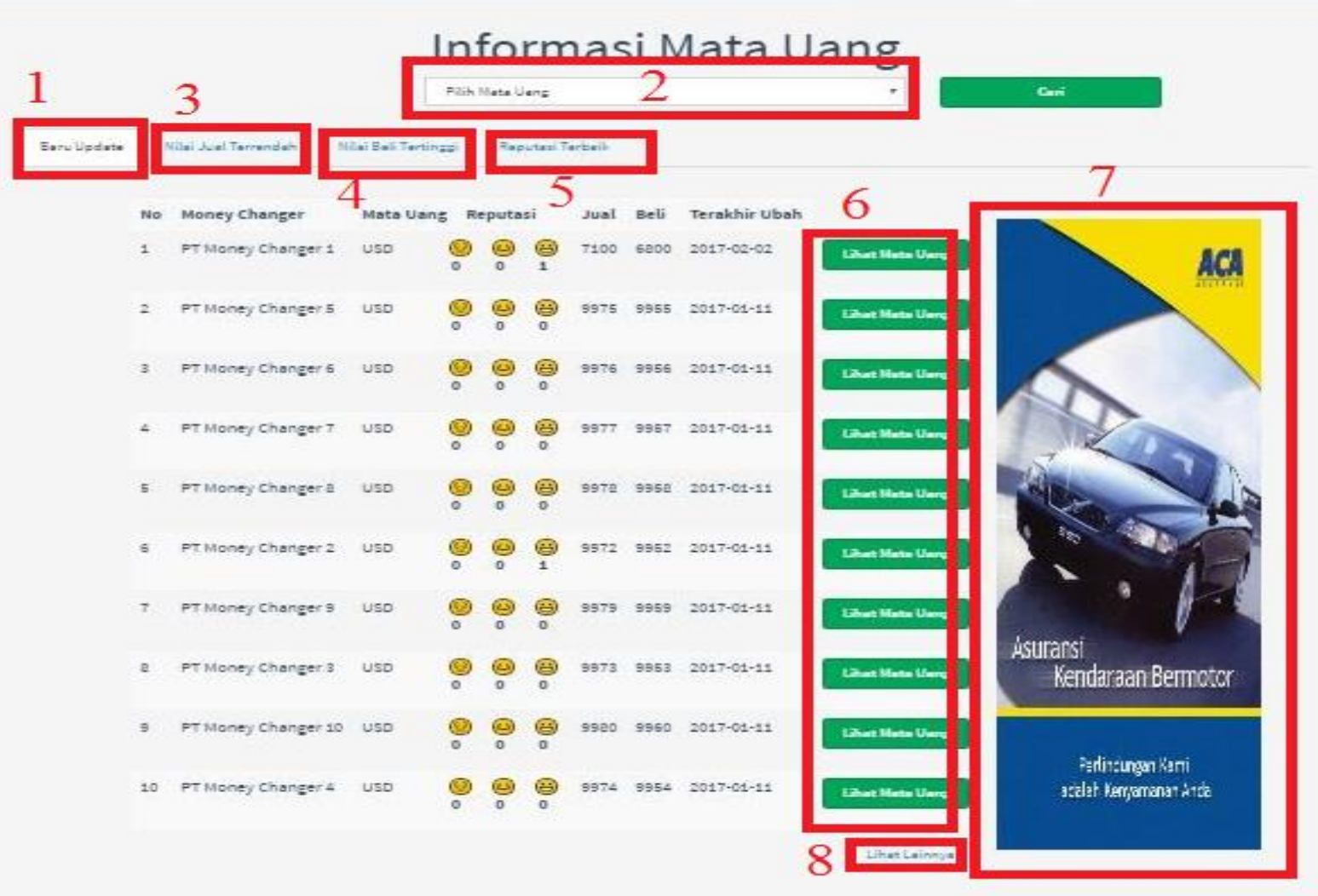

Sumber: (anzaludin, 2019)

Gambar 4. Tampilan Menu Informasi Valas 


\section{KESIMPULAN}

Dengan adanya rancangan sistem informasi ini masyarakat tidak harus datang ke money changer untuk mendapatkan informasi nilai mata uang yang disediakan money changer. Pemesanan valuta asing dapat dilakukan secara online melalui sistem informasi ini. Sistem ini akan terus di kembangkan dengan berbagai fitur seperti metode pembayaran menggunakan metode keamanan biometrik dengan dukungan teknologi Artificial Intelligence (AI). Sistem ini dapat menambahkan metode pengambilan mata uang, pelanggan dapat memilih untuk mengambil uang sendiri atau melalui kurir yang di sediakan sistem ini. Pengembangan kedepannya sistem ini tidak hanya tersedia dalam platform web, melainkan juga dalam bentuk aplikasi mobile yang akan mempermudah pelanggan maupun money changer dalam melakukan pemantauan dan transaksi.

\section{DAFTAR PUSTAKA}

Amanda, R., Yasin, H., \& Prahutama, A. (2014). Analisis Support Vector Regression (SVR) dalam Memprediksi Kurs Rupiah terhadap Dollar Amerika Serikat. Jurnal Gaussian, 3(4), 849-858.

APJII. (2017). Penetrasi \& Perilaku Pengguna Internet Indonesia 2017. Asosiasi Penyelenggara Jasa Internet Indonesia, 1-39.

APJII, B. (2018). Survei APJII: Penetrasi Internet di Indonesia Capai 143 Juta Jiwa. Apjii Available at: https://apiii. or. id/downfile/file/ BULETINAPJIIEDISI22Maret2018. pdf.

Connolly, T. M., \& Begg, C. E. (2005). Database systems: a practical approach to design, implementation, and management: Pearson Education.

Creswell, J. W. (2013). Research design: Qualitative, quantitative, and mixed methods approaches: Sage publications.
Creswell, J. W., \& Clark, V. L. P. (2017). Designing and conducting mixed methods research: Sage publications.

France, R. (2004). Advanced Praise for The Unified Modeling Language Reference Manual: Reading, MA, USA: Addison-Wesley.

Kurniawan, Y. J. (2013). Analisis Pengaruh Tingkat Suku Bunga SBI, Inflasi, Harga Minyak Dunia, Harga Emas Dunia, Kurs Rupiah terhadap Dollar Amerika, Indeks Nikkei 225, dan Indeks Dow Jones terhadap Indeks Harga Saham Gabungan. Jurnal Ilmiah.

Nugroho, A. (2009). rekayasa perangkat lunak menggunakan UML dan JAVA: Penerbit Andi.

Sani, A., Rahman, T. K. A., Subiyakto, A. a., \& Wiliani, N. (2019). Combining Statistical and Interpretative Analyses for Testing Readiness and IT Adoption Questionnaire. Paper presented at the SEWORD FRESSH \#1.

Satzinger, J. W., Jackson, R. B., \& Burd, S. D. (2011). Systems analysis and design in a changing world: Cengage learning.

Sibero, A. F. (2011). Kitab Suci Web Programing, MediaKom: Yogyakarta.

Sugiyono. (2017). Metode Penelitian Kebijakan: Pendekatan Kuantitatif, Kualitatif, Kombinasi, $R \& D$ dan Penelitian Evaluasi Bandung: Alfabeta.

Supardi, Y. (2010). Web My Profile dengan Joomla 1.5. $x$ : Elex Media Komputindo.

Triyono, T. (2008). Analisis Perubahan Kurs Rupiah Terhadap Dollar Amerika.

Wiguna, I. B. W. S. (2014). Pengaruh Devisa, Kurs Dollar As, Pdb Dan Inflasi Terhadap Impor Mesin Kompressor Dari China. E-Jurnal Ekonomi Pembangunan Universitas Udayana, 3(5), 44445.

Yudiastra, P. P., \& Darma, G. S. (2015). Pengaruh Penggunaan Teknologi Informasi, Disiplin Kerja, Insentif, Turnover Terhadap Kinerja Pegawai. Jurnal Manajemen Bisnis, 12(1), 151-176. 